\title{
Malaysian Students' Manifestation of Cultural Adaptation and Resilience during Their Sojourn in Germany
}

\author{
Mohd Najib Redzuan Lee ${ }^{1}$, Andanastuti Muchtar ${ }^{1}$, Shahrum Abdullah $^{1} \&$ Khairul Anwar Mastor ${ }^{2}$ \\ ${ }^{1}$ Centre for Engineering Education Research, Faculty of Engineering and Built Environment, Universiti \\ Kebangsaan Malaysia, Selangor, Malaysia \\ ${ }^{2}$ Centre for General Studies, Universiti Kebangsaan Malaysia, Selangor, Malaysia \\ Correspondence: Andanastuti Muchtar, Centre for Engineering Education Research, Faculty of Engineering and \\ Built Environment, Universiti Kebangsaan Malaysia, 43600 UKM Bangi, Selangor, Malaysia. Tel: \\ 60-3-8921-6520. E-mail: muchtar@eng.ukm.my; tutimuchtar@gmail.com
}

Received: September 24, 2012 Accepted: November 7, 2012 Online Published: November 30, 2012

doi:10.5539/ass.v8n16p96 URL: http://dx.doi.org/10.5539/ass.v8n16p96

\begin{abstract}
The cultural adaptation process manifested by students enrolled in the double-degree programme at the Universiti Kebangsaan Malaysia (National University of Malaysia) and the University of Duisburg-Essen (UDE) in 2009 to 2010 was investigated in this study. The concept of resilience was also examined using two standard psychometric tools, namely, the Big Five Inventory and the Rosenberg self-esteem scale. In this study, the changes in both the personality, behaviour and self-esteem of the students based on a theoretical adaptation framework were amplified. Analyses were presented in a frequency computational form to compare the changes in real time. The students' adaptation patterns were found linked to their period of stay at the UDE.
\end{abstract}

Keywords: adaptation, big five inventory (BFI), Rosenberg self esteem (RSE), double degree

\section{Introduction}

Engineering education throughout the world will change as the prevailing need to acquire better engineers gradually increases. The demands on an engineer would no longer solely involve paper qualifications but would extend to other attributes, such as the ability to work as a team player, communicate and share ideas with different people of various backgrounds, and adapting to new surroundings (Downey et al., 2006). The internationalisation of higher education, therefore, becomes a priority.

In Malaysia, the National University of Malaysia (Universiti Kebangsaan Malaysia, UKM) has had a strong collaboration with the University of Duisburg-Essen (UDE) in Germany for more than a decade. As partners, both universities have jointly established the UKM-UDE double-degree programme as an attempt to provide international exposure to their students. For the Malaysian students, this opportunity is appropriate, given the sharp contrast of Malaysia with Germany in terms of physical weather, cost of living, classroom education, cultural practice, or even language of interaction. After having run for about ten years, the general perception is that the double-degree programme has been successful in producing highly skilled engineering graduates with an international flavour.

With more and more students joining the programme, investigating the influence of such a programme on the engineering students became imperative. However, thus far, no research has been conducted longitudinally to analyse the cultural adaptation process of the UKM-UDE students. Therefore, this work intends to analyse the adaptation process by amplifying the scores using two empirical instruments, namely, the Big Five Inventory and the Rosenberg self-esteem questionnaire. In addition, the discussion on the data collected on the UKM-UDE students will focus on the dynamic cultural adaptation and resilience aspects to gain a greater understanding of the conditions of the UKM-UDE students throughout the double-degree programme.

\section{Method}

\subsection{Instrument and Measurement of Research}

This study uses two empirical cognitive-based research assessment tools namely (1) the Big Five Inventory (BFI) designed by John, Danahue, and Kentle in 1991 (Ashton, 1998; Church \& Burke, 1994; Loehlin et al., 1998), 
and (2) the Rosenberg self-esteem (RSE) scale developed by Rosenberg in 1965 (Blatný, Urbánek, \& Osecká, 2006; McKnight et al., 2010; Roth et al., 2008). The alpha reliability of the BFI is calculated to be 0.27 for the extraversion domain, 0.43 for the neuroticism domain, 0.68 for the openness domain, 0.67 for the conscientiousness domain, and 0.62 for the agreeableness domain. In addition, the alpha reliability of the RSE scale is measured to score 0.68 for the positive self-esteem domain, and 0.72 for the negative self-esteem domain. The BFI assessment tool investigates the personality domain of the behaviour manifested by the UKM-UDE students whereas the RSE tool explores the reason behind such behaviour.

Theoretically, an affective-based approach does not only regard the cause and effect of resilience but also the thinking process that occurs within an individual or group (McKnight et al., 2010; Zautra, 2009; Zautra et al., 1999).

Data are assessed for the significance test by using Cohen's (d) measurement, which indicates significant changes through the mean score and the standard deviation. Cohen's (d) analysis is a method (that uses mean value and standard deviation) invented for the purpose of conducting an effect-size analysis. This type of analysis is recognised and recommended by the American Psychological Association (Malgady, 2007; Sibley \& Duckitt, 2008). The formula for calculating the coefficient of Cohen's (d) is:

$$
\mathrm{d}=\frac{\text { mean difference }}{\text { standard deviation }}=\frac{u_{2}-u_{1}}{\sigma}
$$

where $\mu_{2}$ and $\mu_{1}$ represent the mean for items in group 2 and group 1, respectively; and $\sigma$ represents standard deviation in either group (assuming that both groups have the same sample size) (Algina et al., 2005; Dell'Acqua et al., 2006; Zhao \& Seibert, 2006).

The interpretation of Cohen's $(d)$ value is based on three scales: 1) for value less than 0.2 (small); 2$)$ for value less than 0.5 to more than 0.2 (medium); and 3) for value more than 0.5 to 2.0 (large) (Algina et al., 2005; Dell'Acqua et al., 2006; Zhao \& Seibert, 2006). Thus, these scales represent the degree of significance of the value difference if a comparison is made. This method also enables researchers to identify whether the mean difference between one data and another is random or meaningful.

\subsection{Sample}

The participants in this study were UKM-UDE engineering students belonging to batch 2009 to 2010 ( $\mathrm{n}=12$ ). Data were gathered in September 2009, November 2009, February 2010, June 2010, October 2010, and December 2010. The data reflect the behavioural changes that occurred during these periods.

\subsection{Cultural Adaptation Frameworks}

Acculturation emphasises two significant elements that determine the standard outcome of adaptation research: (1) contact with different cultural practices, and (2) psychological manifestation of adaptation to the new environment. The objective of an acculturation study is to determine how adaptation is viewed. To date, the most common ways to study the process of adaptation are: (1) acculturation schematisation (theory-based approach) (Milton, 1961), and (2) acculturation as a dynamic process (application-based approach) (Kelvin, 1970).

The schematisation of acculturation is viewed as a linear process of assimilation in another culture (Berry et al., 1987). The author of schematisation of acculturation is said to be biased toward the "melting pot" theory. However, the second perspective, which focuses on the dynamics of cultural adaptation, is preferred because it includes all factors that make human beings fit to live in a new environment. Deculturation and enculturation, which refer to unlearning the original culture and learning the new one, respectively, are exhibited continuously by people over time (Gudykunst \& Ting-Toomey, 1988).

A previous article (Berry, 1998; Kazarian \& Evans, 1998) reported five theories used in formulating a conceptual framework. These theories are: (1) the fusion model, which pertains to the emergence of a new culture; (2) the alternation model, which focuses on behaviour associated with a certain cultural context; (3) the assimilation model, which is an interactive model of an ongoing cultural absorption process from the original culture into the dominant one, resulting in the loss of the original identity; (4) the acculturation model, which is similar to the assimilation model but emphasises the retention of the original culture; and (5) the multicultural model, which underscores the existence of a pluralistic society wherein a smaller group maintains its social identity while interacting with a larger group. The pluralistic model focuses on the smaller group's affective, cognitive, and behavioural changes triggered by their coexistence with a larger group. These changes can be considered as part of the acculturation process, which assumes that (1) the individual is free to choose a certain type of adaptation, and (2) environmental conditions have forced him or her to take on one of the five models. 


\subsection{Resilience Frameworks}

The study of resilience generally measures the dynamic adaptation process triggered by different cultural contacts (Zautra, 2009; Zautra et al., 2010). This study classifies resilience into two categories. The first category is recovery from risk. This process involves recovering from a stressful event resulting from change. Although this process appears favourable, no assessment tool is currently capable of comprehending the true meaning of recovery. In assessing resilience, the time and thoroughness needed to overcome a stressful event must be considered. Recovery experiences are closely observed to capture the true meaning of resilience.

The second classification is the sustaining pursuit of the positive. This process involves applying the concept of reserve capacity, in which a person adapts to fundamental changes in his or her surroundings (Barnett, 2001; Connolly et al., 2000; McMillen, 1999). A study was previously conducted on a patient undergoing episodes of pain and stress. Results of the study show that such experience dictates the levels of a person's positive or negative emotional states. Resilience, in this sense, may be regarded as the amount of stress a person can endure before attitudinal change occurs.

\section{Results and Discussion}

Determining the type of adaptation experienced by the students is crucial. A study conducted by a team of researchers from the Chinese University of Hong Kong implies the importance of recognising adaptation identifiers as indicators of coping and changing rather than linking them to the predictor of stress on their sample psychological condition (Wu \& Mak, 2012). This understanding may facilitate the improvement of the double-degree programme to make it more suitable to the background of the participants. The experience of the UKM-UDE students can be classified as sojourner adaptation. Their stay at a foreign university was temporary, ending upon the completion of their studies. Thus, the probability of retaining their original identity, with only minimal changes, is high. However, the case of the UKM-UDE students meets the requirements of adaptation study, namely, (1) contact with different cultural practices, and (2) manifestation of behavioural changes arising from their stay in new surroundings.

The phenomenon of adaptation manifested by the UKM-UDE students is reflected in the scores presented in Figure 1.

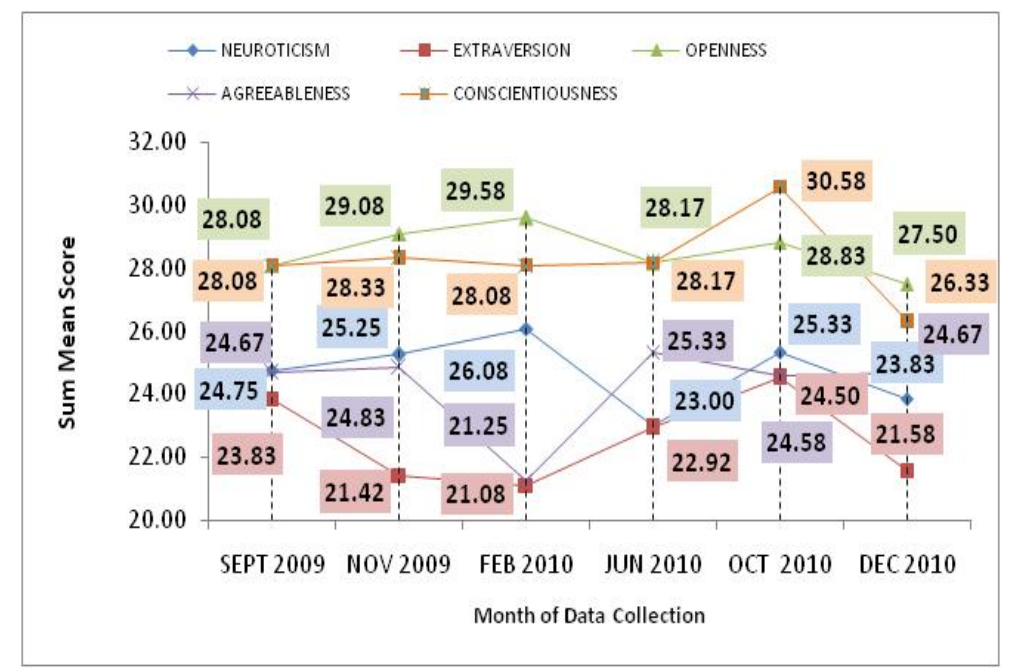

Figure 1. Pattern of neuroticism, extraversion, openness, agreeableness, and conscientiousness of the UKM-UDE sample

As shown in Figure 1, the five domains (that is, neuroticism, extraversion, openness, agreeableness, and conscientiousness) exhibit different levels of personality scores for the periods of September to November 2009, November 2009 to February 2010, February to June 2010, June to October 2010, and October to December 2010. Changes in personality domains prove that the students experience behavioural changes caused by their stay in Germany. A similar study, which uses personality as a measurement indicator of coping at the New York University in the United States, suggests that personality change shows that the samples' choice of overcoming stress may be linked with the condition of their behaviour (Bolger \& Schilling, 1991; Bolger \& Zuckerman, 1995). Thus, for this case study, the changes in scores from one point of collection to another may also indicate the process of overcoming and adapting to the UDE environment. 
The score in the neuroticism domain in Figure 1 increased slightly until February 2010, and subsequently dropped in June 2010. However, the neuroticism domain mildly increased in October 2010, and subsequently decreased in December 2010. Despite this, an opposite reflection of the neuroticism pattern is observed in the extraversion domain from September to June 2010. The extraversion score dropped during the period from September 2009 to February 2010, and then increased in June 2010. On the contrary, the increase and decrease in extraversion were similar to that in neuroticism from October to December 2010.

The period of September 2009 to February 2010 was observed as the time when the UKM-UDE students attempted to get accustomed to the physical and cultural environments of the host country. Thus, an increase in neuroticism explains the stage in which the students experienced the adaptation process. The behaviour of the extraversion score decreases as the neuroticism score increases. This result forms part of the entire effect of adapting to a new lifestyle. In addition, an increase in neuroticism may cause a decrease in extraversion. This result shows that the extraversion domain, known as the behaviour of socialising with the new environment, may be affected by depression, anxiety, or even neuroticism.

However, a different pattern emerged from June 2010 to December 2010. This new pattern displays adaptable behaviour in which the students' socialisation may no longer be subjected to feelings of depression. Moreover, the pattern may be a sign of the way the students cope with challenges without affecting their interaction with those around them. This pattern of adaptive behaviour is similar to the findings of Carver, Scheier, and Weintraub (1989), who formulated a theoretical framework that grouped the behavioural patterns demonstrated by an individual to cope with stress. The researchers concluded that certain behaviour may indicate the success of an individual in overcoming stress (such as turning to religion for comfort or to peers for moral support) (Carver, Scheier, \& Weintraub, 1989).

Although many factors contribute to pattern changes in both the extraversion and neuroticism domains (such as climate change, time adjustment, examinations, and adjustment to new surroundings), the change in both patterns can be deemed as originating from the resilience of the UKM-UDE students. Additionally, the openness score reflects the direct (that is, classroom learning) and indirect (that is, learning to become part of the new contact community) learning processes during the period from November 2009 to February 2010. The increased score in the openness domain shows that the UKM-UDE students struggled not only with the climate (that is, the changing of the seasons) but also with the language barrier. Nevertheless, the students forced themselves to learn new practices. However, a decrease in the openness score from June 2010 to December 2010 may be attributed to the semester break and the beginning of a new semester. A decrease in the openness and neuroticism scores in June 2010 may be attributed to the fact that the students did not have to worry about classes for that month. However, the neuroticism domain score rose as the new semester commenced in October 2010.

The scores in conscientiousness and agreeableness show no significant change. In a study on the experience of an Indonesian student in Germany (Karcher \& Etienne, 1991), the researchers explained the absence of flexibility and freedom in the new environment, which the student used to enjoy in his country. The UKM-UDE students might have gone through a similar predicament, as represented by a stable curve on both the conscientiousness and agreeableness domains.

Cohen's $(d)$ for all data in Figure 1 is presented in Figure 2. The steeper slopes in Figure 2 reveal that the data gathered between collections are significantly high. Figure 3 shows the pattern of positive and negative self-esteem scores periodically from September 2009 to December 2010.

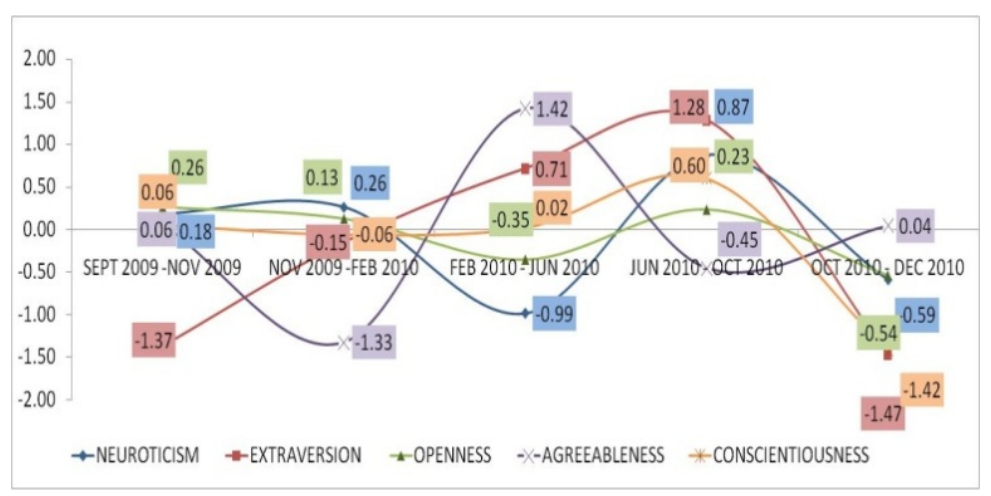

Figure 2. Pattern of the UKM-UDE students' BFI Cohen's $(d)$. 


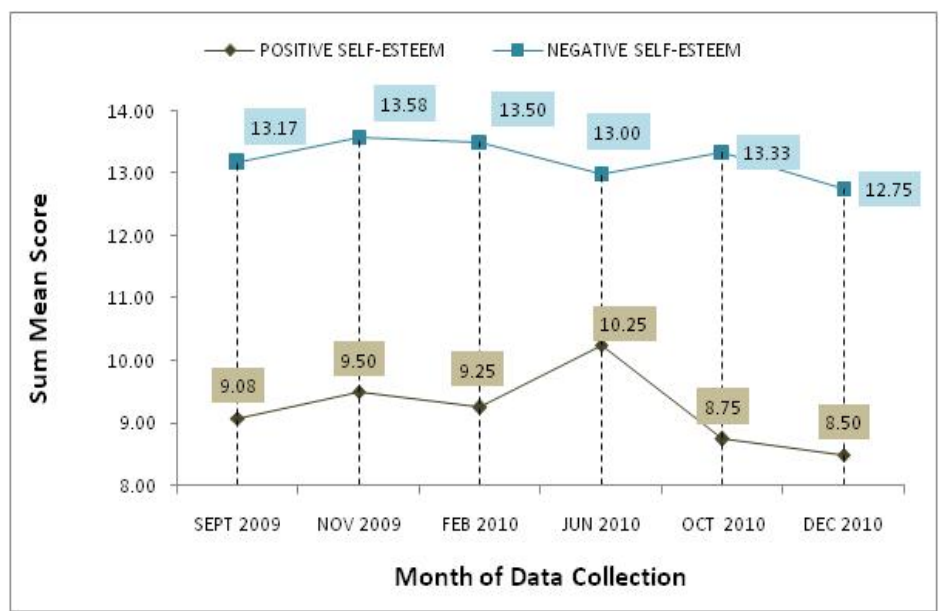

Figure 3. Pattern of positive self-esteem and negative self-esteem of the UKM-UDE sample

The self-esteem scores reported in Figure 3 illustrate the cognitive process experienced by the UKM-UDE students during their stay in Germany. A previous work (Muchtar et al., 2011) mentioned that self-esteem functions as a filtering mechanism of a particular behaviour. The study stated that each score, whether positive or negative self-esteem, may be related to the increase and decrease in the BFI personality domain scores of extraversion and neuroticism. The reason is that the self-esteem score can be used to measure the drive of certain behaviour (Francis \& James, 1996; Fraser et al., 1999; Rosenberg, 1965). The neuroticism domain score increased as the negative self-esteem mean score percentage from September 2009 to February 2010 increased. On the contrary, the score in the extraversion domain increased as the positive self-esteem curve increased from September 2009 to December 2010.

Figure 4 displays the pattern of significance for the RSE scale of the UKM-UDE students. The figure shows that the significance level for positive self-esteem appears to be constantly changing to either a positively high or a negatively high score.

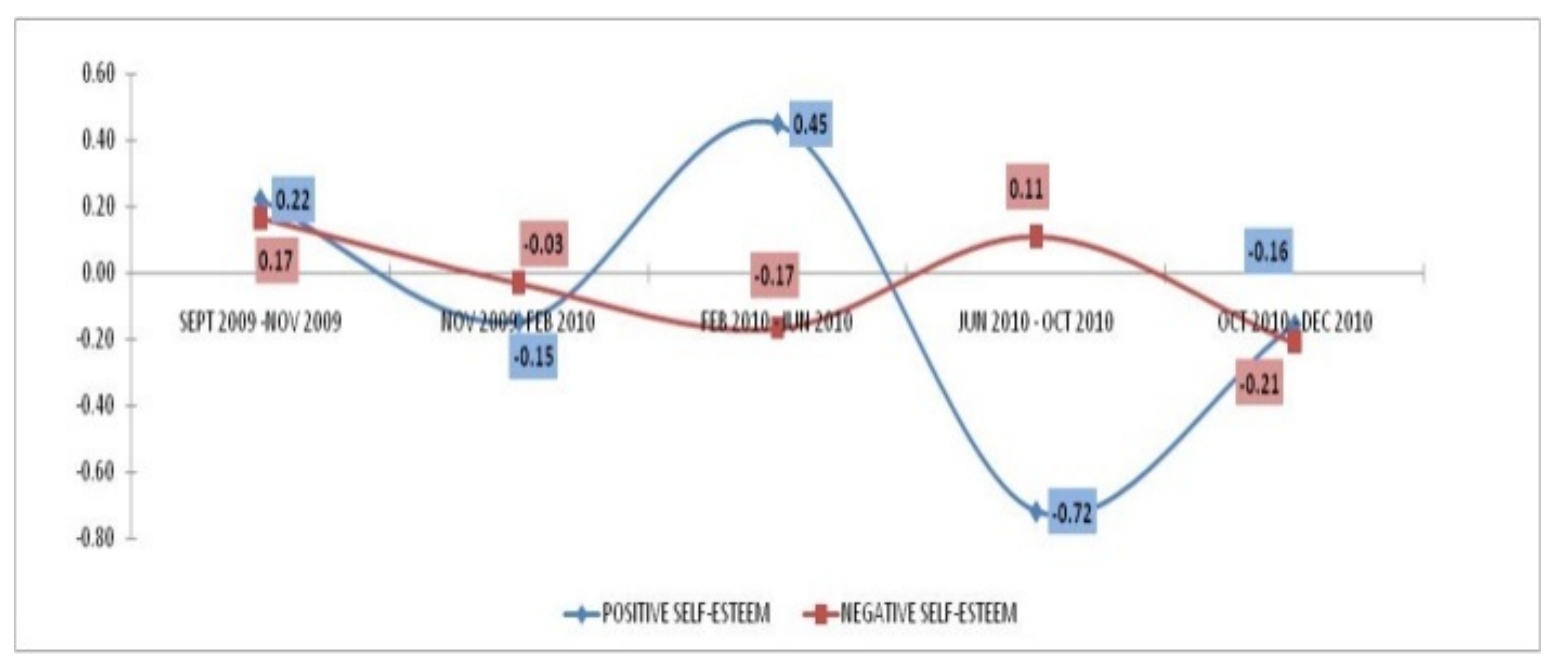

Figure 4. Pattern of the UKM-UDE students' RSE Cohen's $(d)$

Based on the results presented in Figures 1 to 4, the UKM-UDE students fit the profile of a dynamic acculturation process. Although a number of changes may be viewed as signs of assimilation (that is, small changes in the agreeableness and conscientiousness domain scores), the assimilation process is unlikely to occur within a short period.

However, the most difficult question lies in determining the type of resultant adaptation model for the UKM-UDE students (such as fusion, alternation, assimilation, acculturation, or multicultural models). Aside from the fact that the UKM-UDE students experienced adaptation within a temporary period, they are believed to have retained their original culture because of several key factors, such as the presence of a UKM office at the UDE, support groups of UKM students from previous batches and a growing Malaysian student community in 
Germany. These factors may influence the resultant multicultural or acculturation model.

In a study on self-determination, Ryan and Deci (2000) argued the difference between the nature of natural resilience and the facilitation of motivation. They emphasised the importance of both factors in influencing the outcome of an individual's well-being. Similar to that study, the present study on the adaptation of the UKM-UDE students may distinguish the areas of improvement that the students could focus on. Although assumptions were designed to predict the adaptation process of the UKM-UDE students, conducting data collection once the subjects have completed their studies remained crucial. This process is a significant feature of this research, given that the prevailing understanding of the students' adaptive behavioural pattern may lead to certain improvements in the current academic programme.

\section{Conclusion}

This study of the resilience and adaptation process of the UKM-UDE students has shown that the resultant model has a high probability of fitting the profile of the acculturation or multicultural model. However, as the adaptation process continues, the final adaptation model will only be revealed after a long period. Despite this, based on the presented pattern of personality and self-esteem results, this study demonstrates that the UKM-UDE students have acquired a certain degree of positive resilience.

\section{Acknowledgements}

The authors would like to acknowledge Universiti Kebangsaan Malaysia (UKM) for research sponsorship under grant PTS-2011-152 and PTS-2011-157. This work is supported by the Centre for Engineering Education Research, Faculty of Engineering and Built Environment, Universiti Kebangsaan Malaysia, Bangi, Selangor, Malaysia.

\section{References}

Algina, J., Keselman, H. J., \& Penfield, R. D. (2005). An alternative to Cohen's standardized mean difference effect size: A robust parameter and confidence interval in the two independent groups case. Psychological Methods, 10(3), 317-328. http://dx.doi.org/10.1037/1082-989X.10.3.317

Ashton, M. C. (1998). Personality and job performance: The importance of narrow traits. Journal of Organizational Behavior, 19(3), 289-303. http://dx.doi.org/10.1002/(SICI)1099-1379(199805)19:3<289::AID-JOB841>3.0.CO;2-C

Barnett, J. (2001). Adapting to climate change in Pacific Island countries: The problem of uncertainty. World Development, 29(6), 977-993. http://dx.doi.org/10.1016/S0305-750X(01)00022-5

Berry, J. W. (1998). Acculturation and health: Theory and research. In Shahé S. Kazarian, \& David R. Evans (Eds.), Cultural clinical psychology: Theory, research, and practice (pp. 39-57). New York, NY, US: Oxford University Press.

Berry, J. W., Kim, U., Minde, T., \& Mok, D. (1987). Comparative studies of acculturative stress. International Migration Review, 21(3), 491-511. http://dx.doi.org/10.2307/2546607

Blatný, M., Urbánek, T., \& Osecká, L. (2006). Structure of Rosenberg's Self-Esteem Scale: Three-factor solution. Studia Psychologica, 48(4), 371-378.

Bolger, N., \& Schilling, E. A. (1991). Personality and the problems of everyday life: the role of neuroticism in exposure and reactivity to daily stressors. Journal of Personality, 59(3), 355-386. http://dx.doi.org/10.1111/j.1467-6494.1991.tb00253.x

Bolger, N., \& Zuckerman, A. (1995). A framework for studying personality in the stress process. Journal of Personality and Social Psychology, 69(5), 890-902. http://dx.doi.org/10.1037/0022-3514.69.5.890

Carver, C. S., Scheier, M. F., \& Weintraub, K. J. (1989). Assessing coping strategies: a theoretically based

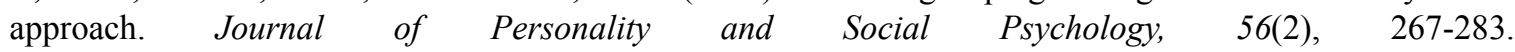
http://dx.doi.org/10.1037/0022-3514.56.2.267

Church, A. T., \& Burke, P. J. (1994). Exploratory and confirmatory tests of the big five and tellegen's three- and four-dimensional models. Journal of Personality and Social Psychology, 66(1), 93-114. http://dx.doi.org/10.1037/0022-3514.66.1.93

Connolly, I. M., Darby, M. L., Tolle-Watts, L., \& Thomson-Lakey, E. (2000). The cultural adaptability of health sciences faculty. Journal of Dental Hygiene : JDH / American Dental Hygienists" Association, 74(2), 
102-109.

Dell'Acqua, R., Sessa, P., \& Pashler, H. (2006). A neuropsychological assessment of dual-task costs in closed-head injury patients using Cohen's effect size estimation method. Psychological Research, 70(6), 553-561. http://dx.doi.org/10.1007/s00426-005-0016-4

Downey, G. L., Lucena, J. C., Moskal, B. M., Parkhurst, R., Bigley, T., Hays, C., \& Nichols-Belo, A. (2006). The globally competent engineer: Working effectively with people who define problems differently. Journal of Engineering Education, 95(2), 107-122.

Francis, L. J., \& James, D. J. (1996). The relationship between Rosenberg's construct of self-esteem and Eysenck's two-dimensional model of personality. Personality and Individual Differences, 21(4), 483-488. http://dx.doi.org/10.1016/0191-8869(96)00095-5

Fraser, M. W., Richman, J. M., \& Galinsky, M. J. (1999). Risk, protection, and resilience: Toward a conceptual framework for social work practice. Social Work Research, 23(3), 131-143. http://dx.doi.org/10.1093/swr/23.3.131

Gudykunst, W. B., \& Ting-Toomey, S. (1988). Culture and interpersonal communication. Culture and Interpersonal Communication.

Karcher, W., \& Etienne, A. (1991). Studieren im Spannungsfeld zweier Kulturen. Indonesische Studierende an deutschen Hochschulen - Eine Bestandsaufnahme. Bundesminister für Bildung und Wissenschaft, 97,144-148.

Kazarian, S. S., \& Evans, D. R. (1998). Cultural clinical psychology. In Shahé S. Kazarian, \& David R. Evans (Eds.), Cultural clinical psychology: Theory, research, and practice (pp. 3-38). New York, NY, US: Oxford University Press.

Kelvin, P. (1970). The bases of social power. New York: Holt: Rinehart, Winston.

Loehlin, J. C., McCrae, R. R., Costa Jr, P. T., \& John, O. P. (1998). Heritabilities of common and measure-specific components of the big five personality factors. Journal of Research in Personality, 32(4), 431-453. http://dx.doi.org/10.1006/jrpe.1998.2225

Malgady, R. G. (2007). How skewed are psychological data? A standardized index of effect size. Journal of General Psychology, 134(3), 355-359. http://dx.doi.org/10.3200/GENP.134.3.355-360

McKnight, P. E., Afram, A., Kashdan, T. B., Kasle, S., \& Zautra, A. (2010). Coping self-efficacy as a mediator between catastrophizing and physical functioning: Treatment target selection in an osteoarthritis sample. Journal of Behavioral Medicine, 33(3), 239-249. http://dx.doi.org/10.1007/s10865-010-9252-1

McMillen, J. C. (1999). Better for it: How people benefit from adversity. Social Work, 44(5), $455-467$. http://dx.doi.org/10.1093/sw/44.5.455

Milton, M. G. (1961). Assimilation in America: Theory and reality. Daedalus, 90(2), 263-285.

Muchtar, A., Redzuan Lee, M. N., Hunger, A., Mastor, K. A., \& Abdullah, S. (2011). Pattern of changes in personality traits and selfesteem among UKM-UDE Double Degree Students. Paper presented at the Global Engineering Education Conference Amman, Jordan. http://dx.doi.org/10.1109/EDUCON.2011.5773229

Muchtar, A., Redzuan Lee, M. N., Hunger, A., Mastor, K. A., Abdullah, S., Sulehan, J., \& Jusdi, M. (2010). Investigation on the Personality Development of Students Enrolled in UKM-UDE Double Degree Programme. Paper presented at the The 2nd International Congress on Engineering Education 2010 (ICEED 2010), Bandar Sunway, Malaysia.

Rosenberg, M. (1965). Society and the Adolescent Self-image. Princeton, NJ: Princeton University Press.

Roth, M., Decker, O., Herzberg, P. Y., \& Brähler, E. (2008). Dimensionality and norms of the Rosenberg self-esteem scale in a German general population sample. European Journal of Psychological Assessment, 24(3), 190-197.

Ryan, R. M., \& Deci, E. L. (2000). Self-determination theory and the facilitation of intrinsic motivation, social development, and well-being. American Psychologist, http://dx.doi.org/10.1037/0003-066X.55.1.68

Sibley, C. G., \& Duckitt, J. (2008). Personality and prejudice: A meta-analysis and theoretical review. Personality and Social Psychology Review, 12(3), 248-279. http://dx.doi.org/10.1177/1088868308319226 
Wu, E. K. Y., \& Mak, W. W. S. (2012). Acculturation process and distress: Mediating roles of sociocultural adaptation and acculturative stress. Counseling Psychologist, $40(1), \quad 66-92$. http://dx.doi.org/10.1177/0011000011410893

Zautra, A. J. (2009). Resilience: One part recovery, two parts sustainability. Journal of Personality, 77(6), 1935-1943. http://dx.doi.org/10.1111/j.1467-6494.2009.00605.x

Zautra, A. J., Hamilton, N. A., \& Burke, H. M. (1999). Comparison of stress responses in women with two types of chronic pain: Fibromyalgia and osteoarthritis. Cognitive Therapy and Research, 23(2), 209-230. http://dx.doi.org/10.1023/A:1018735413411

Zautra, A. J., Hall, J. S., \& Murray, K. E. (2010). Resilience; A New Definition of Health for People and Communities. In J. W. Reich, A. J. Zautra, \& J. S. Hall (Eds.), Handbook of Adult Resilience (pp. 3-29). New York: The Guilford Press.

Zhao, H., \& Seibert, S. E. (2006). The big five personality dimensions and entrepreneurial status: A meta-analytical review. Journal of Applied Psychology, 91(2), 259-271. http://dx.doi.org/10.1037/0021-9010.91.2.259 